\title{
Problems in Remote Accounting Processing of Construction Enterprises and Their Solutions
}

\author{
Xuanjie Liu \\ Accounting Department of Management College, Changchun University \\ 6543 Weixing Road, Changchun 130022, China \\ E-mail: 346732788@qq.com \\ Zhigang Cheng \\ Accounting Department of Management College, Changchun University \\ 6543 Weixing Road, Changchun 130022, China \\ Tel: 86-431-8525-0360Ｅ-mail: lcyxpy@126.com \\ Fengyu Liu \\ Accounting Department of Management College, Changchun University \\ 6543 Weixing Road, Changchun 130022, China \\ Tel: 86-431-8525-0360Ｅ-mail: 1xjwyl@126.com
}

Received: January 17, $2012 \quad$ Accepted: February 21, $2012 \quad$ Published: April 1, 2012

doi:10.5539/ass.v8n4p268

URL: http://dx.doi.org/10.5539/ass.v8n4p268

\begin{abstract}
Aiming at the problems in respect of security, importance and timeliness brought by evidence transmission in remote accounting processing of construction enterprises, this paper tentatively puts forward solutions including temporary entry in book based on photographs, increasing stationed accountant(s) and use outer network or data conversion technique to realize data transmission, and employing financial representatives, etc.
\end{abstract}

Keywords: Remote accounting business, Original evidence, Booking evidence, Cloud storage

\section{Presentation of problems}

In one of actual research/survey to a construction enterprise (hereinafter shortened as "this enterprise"), which was offering aid construction of Beichuan, the hit area in 5.12 earthquake and the construction project group was very far from the headquarter, the cost accountant of this enterprise, Chen, has ever asked a question: when revenue of this enterprise totally enters the basic account in bank, while all expenditures necessary for construction work are paid by the bank opened in the construction place, during the final accounting for revenue, following difficulties will come out in financial processing: the construction project group had many charges against revenue, in other places and part of expenditure cost was rather high, e.g. expenditures such as acquiring raw materials and employing local workers or employees in local place, etc. considered from the importance principle, such expenditures have influenced the enterprise's profit greatly, and must be entered into the account and disclosed timely; considered from accounting aging, such expenditures must be reflected in the year that they incurred. Considered from taxation, such expenditures should also be written into the cost of the same year, otherwise, the matching relationship will be influenced, and the profit may be highly increased falsely or even worse, resulting in false profit (actual loss), the tax basis will then be influenced seriously. However, if we consider based on accounting practice, the occurrence of business transaction and relevant original evidence is in other places far from the headquarter, for the reason of security and timeliness, these information cannot be transmitted timely (the security of sending by post or express delivery is not so absolutely reliable, and to take remedial measures for the missing of some evidence is extremely difficult.) and financial department cannot book the account. 


\section{Adoptable solutions}

After a long thought and discussion with many experts and scholars, the author puts forward following solutions which are recognized and adopted by the enterprise:

\subsection{Remote temporary entering into account}

This is the initial solution that the author presented and it is also the one that the enterprise adopted later.

\subsubsection{Making responsibility clear and definite}

The original evidences acquired by outside project groups during their transactions are signed by the responsible persons, project leader and certifier, and also the dates are also signed in the blank space of these evidences. The signer will bear corresponding responsibilities.

\subsubsection{Collect electronic data}

Acquire electronic data photograph of original evidences with scanner or camera (High resolution cell phone may be used if scanner or camera is not available in those construction sites.) and save these data in a specific location of specific devices or PC hard disc for remote transmission.

\subsubsection{Transmit electronic photographs}

These photographs are sent to the financial department of the headquarter by QQ, MSN, Email (large attachment may be used), network hard disc, skype, UC, Group Share, etc., and received by appointed personnel. Meanwhile, backup files, short messages and call recordings, etc, are saved for future reference so that these backup files may provide proves for determining responsibility in case of error during checkout to prove the sender and receiver are both specific personnel. And these backup files cannot be deleted until original evidences are filed. If the personnel and technique is good enough, these photographs may be sent after processed, e.g. encryption and compression processing to prevent from virus's and Hacker's interference. The received electronic photograph data should be marked or saved to a specific location to avoid retransmitting and avail for future reference.

\subsubsection{Replace original evidence to enter book account}

Print out the received remote electronic data, photographs, and enter them into book account instead of original evidences (such photographs should be attached onto the reverse side of accounting evidences with pins or paper clips.) in normal accounting way. Relevant booking evidences and attachments should be saved in a specific clip in specific filing cabinet for an easy search and replacement, but not be filed as normal original evidences; meanwhile, to be registered into the memorandum book stating detailed information including bookkeeping evidence number, original evidence name and serial number, date of entry in account and the date, amount and item that original evidence said, as well as the responsible persons including the operator, acceptance maker and approver.

\subsubsection{Storage of outside original evidences}

The original evidences are the basis of the most legal validity, therefore, they should be kept in a safe place---the received outside original evidences should be kept by specific personnel and should be placed in a save to prevent from missing. When an outside transaction comes to the end, evidences should be collected and put into control as soon as possible. The electronic data, photographs of those original evidences which electronic data has not been acquired should be collected as soon as possible and send to headquarter.

\subsubsection{Filing management}

Check the original evidences one by one when it is accepted; replace formal replacement photographs; cancel the records on the registration book; destroy formal replacement photographs that had been entered in the account; bind the accounting vouchers/evidences in a volume and file them for daily management.

\subsection{Increase outside-stationed accountant posts}

If a construction project group has too many transactions and more accountants are necessary, the number of such accountant need to be considered. If the number are over 2 , normal internal regulations may be applied; if only 1 accountant is assigned, more power (incompatible post restrictions or limits may be widen if necessary, e.g. in network accounting system, if 1 outside-stationed accountant is assigned, different log-in account and power may be set to complete bookkeeping and auditing, the accounting information may enter the database on the server) must be given to him or her for a convenient daily processing. Further, based on secondary account and sub-ledger, send the amount incurred and balance of relevant account to the financial department of headquarter for a summary and treatment. By this way, it ensures a timely accounting treatment of enterprise 
accounting information and also is in favor of a timely binding and filing of evidence documents for the financial department.

The original evidences on which the electronic evidences are based and booking evidences prepared by outside-stationed accountant(s) should be recheck and audited actually by relevant principals when they are submitted to the financial department for filing. In case that any problem is found, Correction by Using Red Ink may be applied for correction. They method may probably result in those mistakes hard to be found timely and also cause the internal work quantity of the enterprise a increase sharply in a short time.

If we use network accounting information system, the outside-stationed project group can be set as an office terminal and network co-working can be done. Should in condition that electronic notes and electronic signature are applied in the future, all accounting work can be completed as if in one office. Nowadays, the technical bottleneck is the security of remote log-on and data transmission. After all, the external network is in high risk of contracting virus and hostile attack. Therefore, Hacker guard settings are very important.

Against such problems caused by external network, currently two methods may be used for completing remote financial software: one is to apply VPN (Virtual Private Network) which is complex to set but very safe, and VPN also requires the support of the enterprise firewall; the other is to make Port Mapping on the firewall, almost all routers or firewalls support this. And the setting is rather easy but security is a little bit lower. The financial staff must set hosts document on their computers when they use external network so as to identify correctly the real IP of the computer at financial software server end. Should ERP network storage under "Cloud"be realized, users would not worry about data missing, software updating or virus acctack, etc. because the "Cloud" service has professional IT team to manage the information, has advanced database to store data, its strict permission administration strategy may help the user and appointed personnel to share data.

I also have another assumption. If remote treatment online cannot be realized, we may install all financial software that are used by the financial department in the local financial computer which the project is located, and transmit the generated database files of same type back to financial department of the company, then entering account can be done timely. As for booking evidence serial number, they can generate automatically or be coded manually. Some financial software has evidence guide-in function, e.g. there is an import tool under UFIDA software's general ledger, it may move evidences into one accounting mode and then line backward the numbers automatically. If the system is defined to line number manually, it may define the evidence number as user required. However, the precondition for doing these operations is that the accounting mode information (data structure of relevant information such as items and departments) should be ensured consistent, then each information of outside project may be moved into the general ledger subsystem and be accounted in normal way monthly.

In my opinion, if there is no evidence import or export function in the financial software in use, based on the current technique, many database may import or export between each other or may import to EXCEL or text file firstly, then import to another database. The only troublesome is that the field sequence in database import and export needs to be processed carefully. For which, we may set the relevant conditions for field sequence by Microsoft query tool in EXCEL.

\subsection{Account by agency bookkeeping}

Finding financial agency company or certified accountants' firm or individual financial personnel as agency in local place where the project construction site is located to keep accounts may save more labor cost than assigning accountant from the headquarter. These agencies' familiarity to the enterprise's affairs is much lower than the accountant staff from the enterprise, but their advantage is that they are the local people and are much easy to contact with relevant administrative departments, e.g. local industrial and commercial administration or taxation department, etc. The other aspects are basically as same as those abovementioned in part 2.2.

\section{Conclusion}

In doing remote accounting information processing for the construction enterprises we have come to the conclusion: as there are no particular rules in laws, regulations or systems, according to the legislative spirits of related laws such as tax laws, company laws, accounting laws together with current digital photography technology, network transmission technology, accounting requirements accounting personnel can reasonably solve problems. Accountants can also further utilize computer terminal technology, data base management, by increasing stationed accountants and employing financial representatives while keeping data transmission and data security to realize remote accounting processing of construction enterprises. 


\section{References}

Chen, Chaoyang \& Zeng, Jianshan. (2007). Application Skills of UFIDA ERP General Ledger System. Inner Mongolia Science and Economy, 11(151), pp. 163-164.

Chen, Tianming. (2010, December). How to Use Financial Software Remotely in Internet. Friend of Accounting, Second Half, p. 64.

Guo, Xiaoxi. (2007, October). Camera Cell Phone strikes Low-End Camera Market. China Science \& Technology Fortune, pp. 76-79.

Jin, Shuhai, Han, Guang, Zhu, Zhiqi, Zuo, Xiaojun \& Liu, Qiang. (1998, June). An Approach for Transferring the Data of Remote Accounting System into ORACLE Database. Hebei Electric Power, pp. 52-54.

Panx. (2011, January). Secret of 10 Top Chat Software in Recent Days. Network and Information, pp. 58-59.

Tao, Lei. A Tentative Research on Library Network Storage under "Cloud". Researches in Library Science (Theory Edition), pp. 66-70.

Tian, Fen. (2009, February). Computer Auditing. Fudan University Press, pp. 46-70.

Wan, Xianzhen \& Wang, Jun. (2011, February). A Practical Approach for Converting Paper Books into Electronic Files with Digital Camera. Computer Study, pp. 62-63.

Wang, Jian \& Yang, Zhendong. (2009, February). Study of Implementation Strategy of Remote Simulation Software for Accounting Teaching. Continue Education Research, pp. 41-44.

Zhang, Qifu \& Sun, Xianshen. (2011, February). 3D Laser Scanner Measuring Method and Prospect Forecast. Beijing Surveying and Mapping, pp.39-42.

Zhang, Ruijun. (2007, October). Computerized Financial Management. China Renmin University Press, pp. 99-114.

Zhu, Xiaoping \& Xu, Hong. (2009, June). Primary Accounting $\left(5^{\text {th }}\right.$ ed). China Remin University Press, pp. $100-117$. 